\title{
Comparative case studies on ring gear fault diagnosis of planetary gearboxes using vibrations and acoustic emissions
}

\author{
Félix Leaman ${ }^{1}(\mathbb{D}) \cdot$ Ralph Baltes $^{1} \cdot$ Elisabeth Clausen ${ }^{1}$ \\ Received: 1 December 2020 / Accepted: 18 February 2021 / Published online: 8 March 2021 \\ (c) The Author(s) 2021
}

\begin{abstract}
The analysis of vibrations and acoustic emissions (AE) are two recognized non-destructive techniques used for machine fault diagnosis. In recent years, the two techniques have been comparatively evaluated by different researchers with experimental tests. Several evaluations have shown that the AE analysis has a higher potential than the vibration analysis for fault diagnosis of mechanical components for certain cases. However, the distance between the AE sensor and the fault is an important factor that can considerably decrease the potential to detect damage and that has not been sufficiently investigated. Moreover, the comparisons have not yet addressed conditions of slow speed that for example are usual for wind turbine gearboxes. Therefore, in this paper we present two comparative case studies that address both topics. Both case studies consider planetary gearboxes with faults in their ring gears. The first case study corresponds to a small planetary gearbox in which the AE and vibration sensors were installed together at two different positions. The second case study corresponds to a full-size wind turbine gearbox in which three pairs of $\mathrm{AE}$ and vibration sensors were installed on the outside of the ring gear from a low-speed planetary stage. The results of the evaluations demonstrate the important influence of the distance between sensors and fault. Despite this, the good results from the AE analysis indicate that this technique should be considered as an important complement to the traditional vibration analysis. The main contribution of this paper is comparing $\mathrm{AE}$ and vibration analysis by using not only experimental data from a small planetary gearbox but also from a full-size wind turbine gearbox. The comparison addresses the topics of proximity of the sensor to the fault and low-speed conditions.
\end{abstract}

Félix Leaman

fleaman@amt.rwth-aachen.de

Ralph Baltes

rbaltes@amt.rwth-aachen.de

Elisabeth Clausen

eclausen@amt.rwth-aachen.de

1 Institute for Advanced Mining Technologies, RWTH Aachen

University, Wüllnerstr. 2, 52062 Aachen, Germany 


\section{Komparative Fallstudien zur Hohlrad-Fehlerdiagnose von Planetengetrieben mittels Schwingungen und Schallemissionen}

\section{Zusammenfassung}

Die Analyse von mechanischen Schwingungen (Vibrationen) und Schallemissionen (Acoustic Emissions, AE) sind zwei anerkannte zerstörungsfreie Prüfmethoden, die zur Fehlerdiagnose von Maschinen eingesetzt werden. In den letzten Jahren wurden die beiden Prüfmethoden von verschiedenen Forschern durch experimentelle Versuche komparativ ausgewertet. Mehrere Auswertungen haben gezeigt, dass die AE-Analyse in bestimmten Fällen ein höheres Potenzial als die Schwingungsanalyse für die Fehlerdiagnose von mechanischen Komponenten hat. Allerdings ist der Abstand des AE-Sensors zum Fehler ein wichtiger Faktor, der das Potenzial zur Schadenserkennung erheblich verringern kann und der bisher nicht ausreichend untersucht ist. Außerdem sind Betriebsbedingungen wie langsame Drehzahl, die üblich bei Getrieben von Windenergieanlagen sind, bei den Auswertungen nicht berücksichtigt worden. Daher werden in dieser Arbeit zwei komparative Fallstudien vorgestellt, die beide Themen ansprechen. Beide Fallstudien betrachten Planetengetriebe mit Fehlern in ihren Hohlrädern. Die erste Fallstudie entspricht einem kleinen Planetengetriebe, bei dem die AE- und Schwingungssensoren gemeinsam an zwei verschiedenen Positionen installiert wurden. Die zweite Fallstudie entspricht einem Windkraftgetriebe voller Größe, bei dem drei Paare von AE- und Schwingungssensoren an der Außenseite des Hohlrads einer langsam laufenden Planetenstufe installiert wurden. Die Ergebnisse der Auswertungen zeigen den großen Einfluss des Abstandes zwischen Sensoren und Fehler. Nichtsdestotrotz weisen die guten Ergebnisse der AE-Analyse darauf hin, dass diese Prüfmethode als eine wichtige Ergänzung zur traditionellen Schwingungsanalyse betrachtet werden sollte. Der Hauptbeitrag dieser Arbeit ist der Vergleich von AE- und Schwingungsanalyse, wobei nicht nur experimentelle Daten eines kleinen Planetengetriebes, sondern auch eines Windkraftgetriebes voller Größe verwendet werden. Der Vergleich befasst sich mit den Themen der Nähe des Sensors zum Fehler und den Bedingungen bei niedriger Drehzahl.

\section{Introduction}

The wind power sector has experienced a rapid growth in recent years due to the increasing need for renewable energy [1]. Therefore, the number of onshore and offshore wind farms in operation and in construction increases constantly. In order to ensure the safe supply of renewable energy and the economic viability of a wind farm, the maintenance of wind turbines and its components is a key point [2]. One of the components that causes longer downtimes when it fails unexpectedly is the gearbox [3]. Due to this, there is a constant need for improving the detection of faults in the gearbox to avoid unplanned shutdowns.

In most wind turbine gearboxes, the vibrations at several positions are periodically monitored in order to detect possible anomalies [4]. These anomalies can be faults in components such as gears or bearings. Vibrations are mechanical oscillations of a body due to dynamic forces acting on it. Common vibration sensors such as accelerometers can normally measure vibrations up to $20 \mathrm{kHz}$ [5]. In gear transmissions vibrations are originated from the gear mesh forces acting between teeth. Faults such as cracks or wear may modify the stiffness of a damaged tooth causing changes in the vibration response from the gear transmission [6].

The analysis of vibration signals is normally carried out by evaluating their Fourier spectra. In this way, the different vibration components can be monitored by analyzing their magnitudes at specific frequencies $[7,8]$. In machines with several components, the spectral analysis allows to identify the faulty component by analyzing the operational frequencies of each component. Although the measurement of vibrations is relatively standard, due to factors such as complex dynamic, structural resonances or slow rotating speeds, the effects of a fault could not be well represented by the vibration signals [9].

Another technique that has been gradually growing in the field of condition monitoring is the acoustic emissions (AE) analysis. The AE are elastic stress waves of high frequency that originate from events such as crack propagation, friction, impacts and plastic deformation, among others [10]. They have frequencies approximately in the range from $20 \mathrm{kHz}$ up to several $\mathrm{MHz}$ [11]. The $\mathrm{AE}$ waves can arrive at the sensor as distinguishable single waves or as waves that are so concentrated that they cannot be distinguished from each other. In the first case one speaks of an AE burst, while in the second case one speaks of continuous AE. In gear transmissions the main source of AE has been attributed to asperities contacts between meshing teeth [12]. In spite of the different explanations by several authors [13, 14], it is relatively clear that continuous $\mathrm{AE}$ is caused by the sliding friction and that $\mathrm{AE}$ bursts are originated as the teeth contact point approaches the pitch point.

The presence of gear damage such as wear or cracks will modify the asperity contacts between meshing teeth. Therefore, the AE analysis in gear transmission allows to detect possible faults in the gears. Similar to the vibration analysis, a spectral analysis can also be carried out for the $\mathrm{AE}$ 
signals. Since they have frequencies much higher than operational frequencies of the components from the gearboxes, their spectral analysis is conducted using the envelope of the signals instead of the signals themselves $[15,16]$. In this way, the fluctuations of the AE energy flow associated with the operational frequencies can be analyzed in a similar way as the spectral analysis for vibration signals.

Some investigations have addressed the good potential of the AE over vibration analysis for gearbox fault diagnosis [17-19]. However, there are two aspects that have not been sufficiently addressed yet. The first aspect is the proximity of the sensor to the fault. Since the AE have much higher frequencies than the vibrations, the attenuation of the AE with the distance is considerably higher than for the vibrations. Besides, the reflection of $\mathrm{AE}$ at body interfaces can considerably decrease the amount of $\mathrm{AE}$ that arrives to the sensor. These observations make that the good potential of $\mathrm{AE}$ for gearbox fault diagnosis can considerably be reduced if the sensor is not near enough to the fault. The second aspect is the evaluation under slow-speed conditions. It is well known that the performance of vibration analysis for detection of gearbox faults is considerably decreased for slow-speed conditions [20, 21]. These conditions are expected, for example, in the planetary stage from wind turbine gearboxes. There are some investigations that suggest the good performance of AE over vibration analysis for fault detection in low speed bearings [22, 23] and spur gears [24]. However, to the best of the authors knowledge, comparisons of both techniques for gear fault diagnosis in planetary stages from wind turbine gearboxes are still a gap in the research field.

Therefore, in this research both of the previously described aspects are considered and analyzed by means of two case studies. The first case study addresses the influence of the proximity of the $\mathrm{AE}$ and vibration sensors to a gear fault in a small planetary gearbox. The second case study presents a comparison between the $\mathrm{AE}$ and vibration techniques for gear fault detection under the slow-speed conditions of a planetary stage from a full-size wind turbine gearbox. Among the different possible faults that can occur, the research focuses on ring gear faults.

\section{Signal analysis}

A spectral analysis based on the Fourier transform allows to identify repetitive patterns in time signals. The Fourier transform of a time signal $x(t)$ is defined as:

$X(f)=\mathcal{F}[x(t)]=\int_{-\infty}^{\infty} x(t) e^{-2 \pi \mathrm{itf}} d t$

where $f$ are the frequencies of those repetitive patterns and $X$ are they magnitudes. The 2 d-representation of both variables corresponds to the well-known spectrum.

Mechanical vibrations are caused by dynamic forces generated by interactions among machine components. Therefore, the application of the Fourier transform is very straightforward for the vibration analysis since the magnitudes $X(f)$ are directly associated with operational frequencies of machine components. Thus, a magnitude change of certain frequency component $X_{k}\left(f_{k}\right)$ can be related to a change of a dynamic force with frequency $f_{k}$ if the frequency response of the system was not altered. Subsequently, the force change can be related to a change in the mechanical condition of certain machine component.

If the Fourier transform is applied to AE signals, the magnitudes $X(f)$ will be associated with the frequencies of the AE waves. These frequencies are much higher than operational frequencies; therefore, the cannot be associated with dynamic forces of machine components. A magnitude change of certain frequency component $X_{k}\left(f_{k}\right)$ will only reflect a change in the mechanism (e.g. crack, friction, impacts) that generates the AE, but the identification of the machine component where this change happens will not be possible.

In order to associate repetitive releases of $\mathrm{AE}$ to operational frequencies, the Fourier transform can be applied to the envelope of the AE signal, which reflects how the $\mathrm{AE}$ energy flows over time. The most straightforward way to estimate the envelope of a signal is with a low-pass filter. The filter is applied to a rectified version of the original signal to obtain the envelope. The cut-off frequency of the filter has a major impact on the result. High cut-off frequencies can produce an envelope with ripples, while low cutoff frequencies provide low sensitivity to sudden amplitude changes. Another method to estimate the envelope is based
Fig. 1 Schema of the planetary gearbox test bench

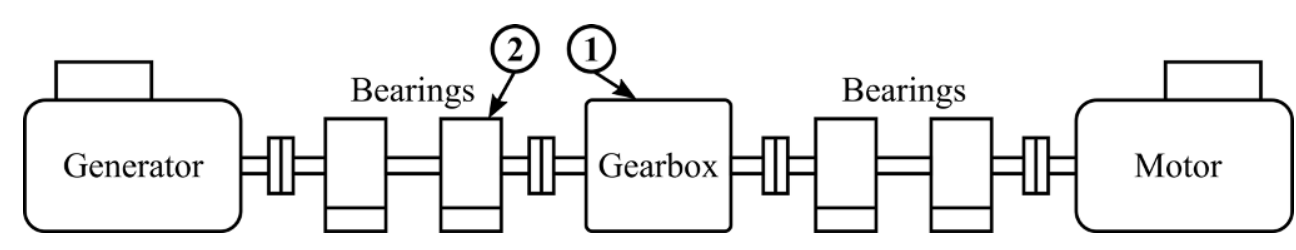




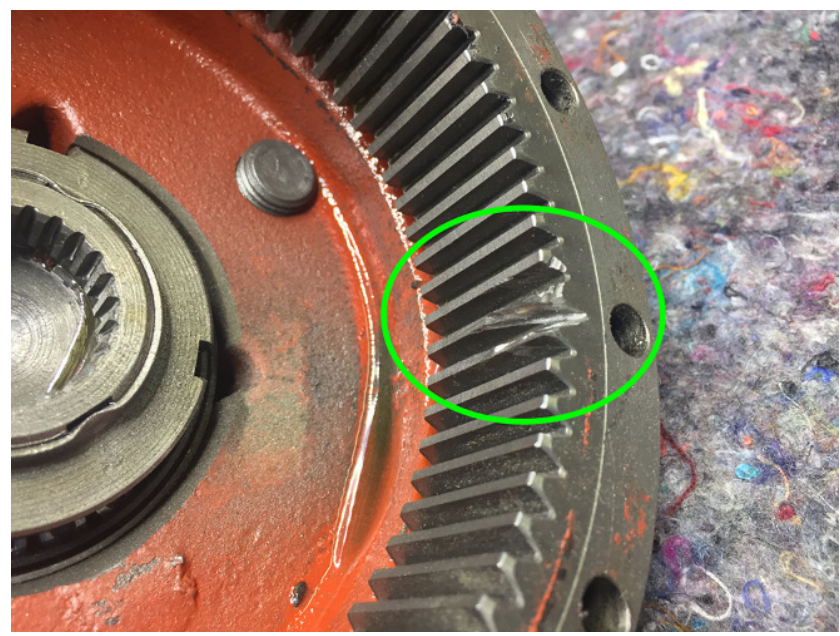

Fig. 2 Fault in the ring gear of the PG

on the Hilbert transform. The Hilbert transform of a time signal $x(t)$ is defined as follows:

$H(t)=\mathcal{H}[x(t)]=\frac{1}{\pi} \int_{-\infty}^{\infty} \frac{x(\tau)}{t-\tau} d \tau$
The analytical signal $x_{a}(t)$ of the original signal $x(t)$ is defined as:

$x_{a}(t)=x(t)+i \mathcal{H}[x(t)]=r(t) e^{i \theta(t)}$

where $r(t)$ and $\theta(t)$ are their modulus and phase, respectively. This modulus $r(t)$ is considered to be an estimation of the signal instantaneous amplitude, i.e. its envelope. The application of the Fourier transform to this envelope leads to the calculation of the envelope spectrum as follows [16]:

$$
\begin{aligned}
\tilde{X}(\tilde{f}) & =\mathcal{F}[r(t)] \\
& =\int_{-\infty}^{\infty}\left\|x(t)+\frac{i}{\pi} \int_{-\infty}^{\infty} \frac{x(\tau)}{t-\tau} d \tau\right\| e^{-2 \pi \mathrm{i} \mathrm{t} \tilde{f}} d t
\end{aligned}
$$

where $f$ are the repetitive frequencies present in the envelope and $X^{\sim}$ are they magnitudes. These repetitive frequencies can be related to operational frequencies of machine components in the case of the $\mathrm{AE}$ analysis.

As mentioned in the previous section, in gear transmissions both $\mathrm{AE}$ and vibrations are originated by the meshing teeth. The originated vibration has a fundamental frequency equal to the gear mesh frequency, while $\mathrm{AE}$ of high frequency are originated repetitively at this same gear mesh frequency. Consider a planetary gearbox with the following number of teeth: $Z_{s}$ for the sun gear, $Z_{r}$ for the ring gear
Fig. 3 Envelope spectra of the $\mathrm{AE}$ signals for both measurement positions

Fig. 4 Spectra of the vibration signals for both measurement positions
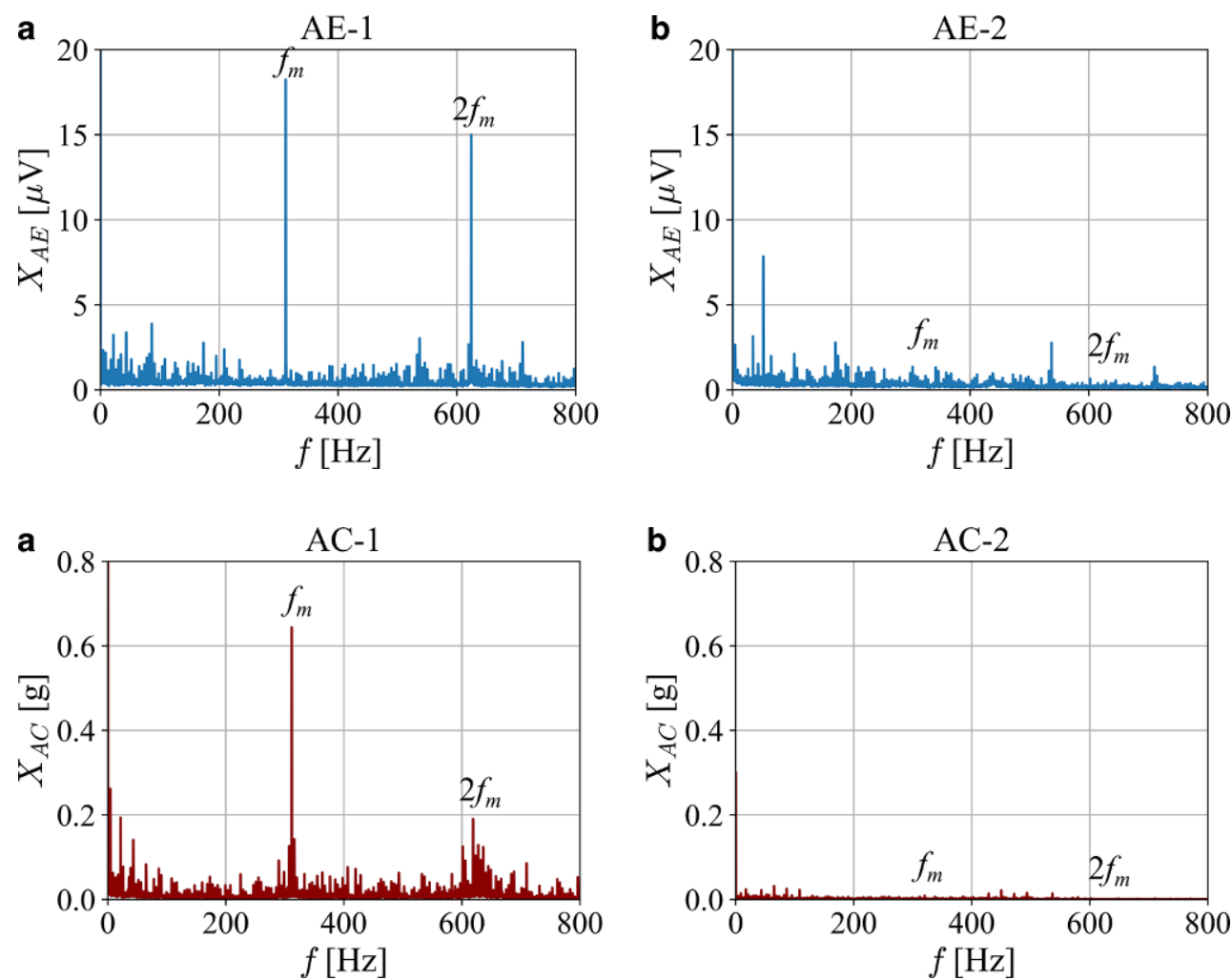
Fig. 5 Schema of the gearbox (a) and measurement position on the planetary stage (b)
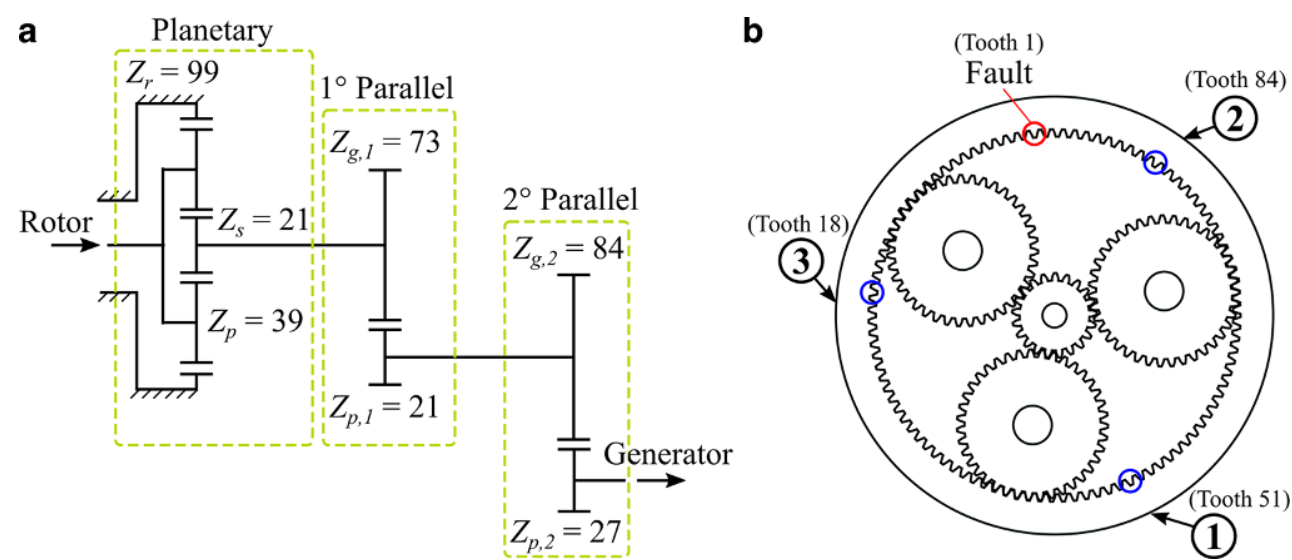

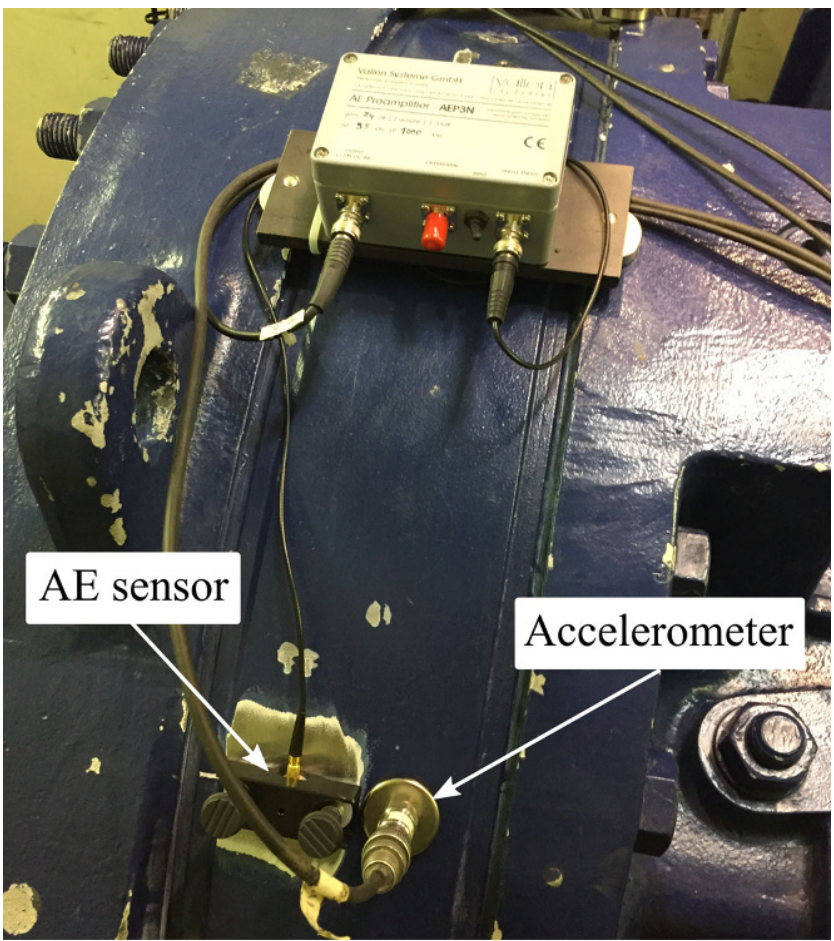

Fig. 6 AE sensor and accelerometer installed outside the ring gear of the planetary stage

and $Z_{p}$ for the planet gears; and with the following rotational frequencies: $f_{s}$ for the sun gear, $f_{p}$ for the planet gears and $f_{c}$ for the planet carrier. Then, the gear mesh frequency $f_{m}$ is calculated as follows [25]:

$f_{m}=\frac{Z_{s} Z_{r}}{Z_{s}+Z_{r}} f_{s}=Z_{r} f_{c}$

Most faulty conditions will increase the amplitude of the vibration and $\mathrm{AE}$ generated by the meshing teeth. Therefore, in a spectral analysis magnitude increases of the gear mesh frequency and harmonics can be associated with gear faults. For the spectral analyses presented in this study, the vibration signals are analyzed using simply the Fourier spectrum, while the AE signals are analyzed using the en-

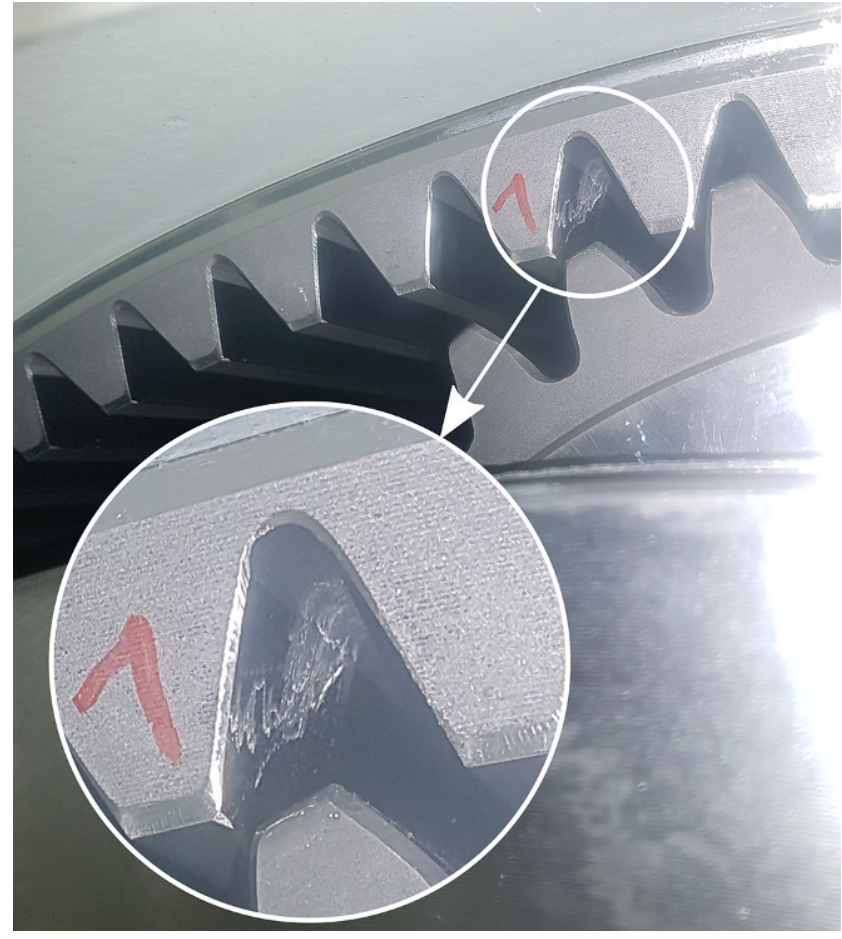

Fig. 7 Fault in the ring gear of the planetary stage

velope spectrum. For both cases the relative magnitudes of the gear mesh frequency and harmonics are considered as indicators of gear damage.

\section{First case study}

\subsection{Procedure}

For the first case study we measured $\mathrm{AE}$ and vibration at two different positions on a small planetary gearbox test bench. A schematic view of the test bench and measurement positions is shown in Fig. 1. The measurement position 1 was located direct on the planetary gearbox, while the mea- 

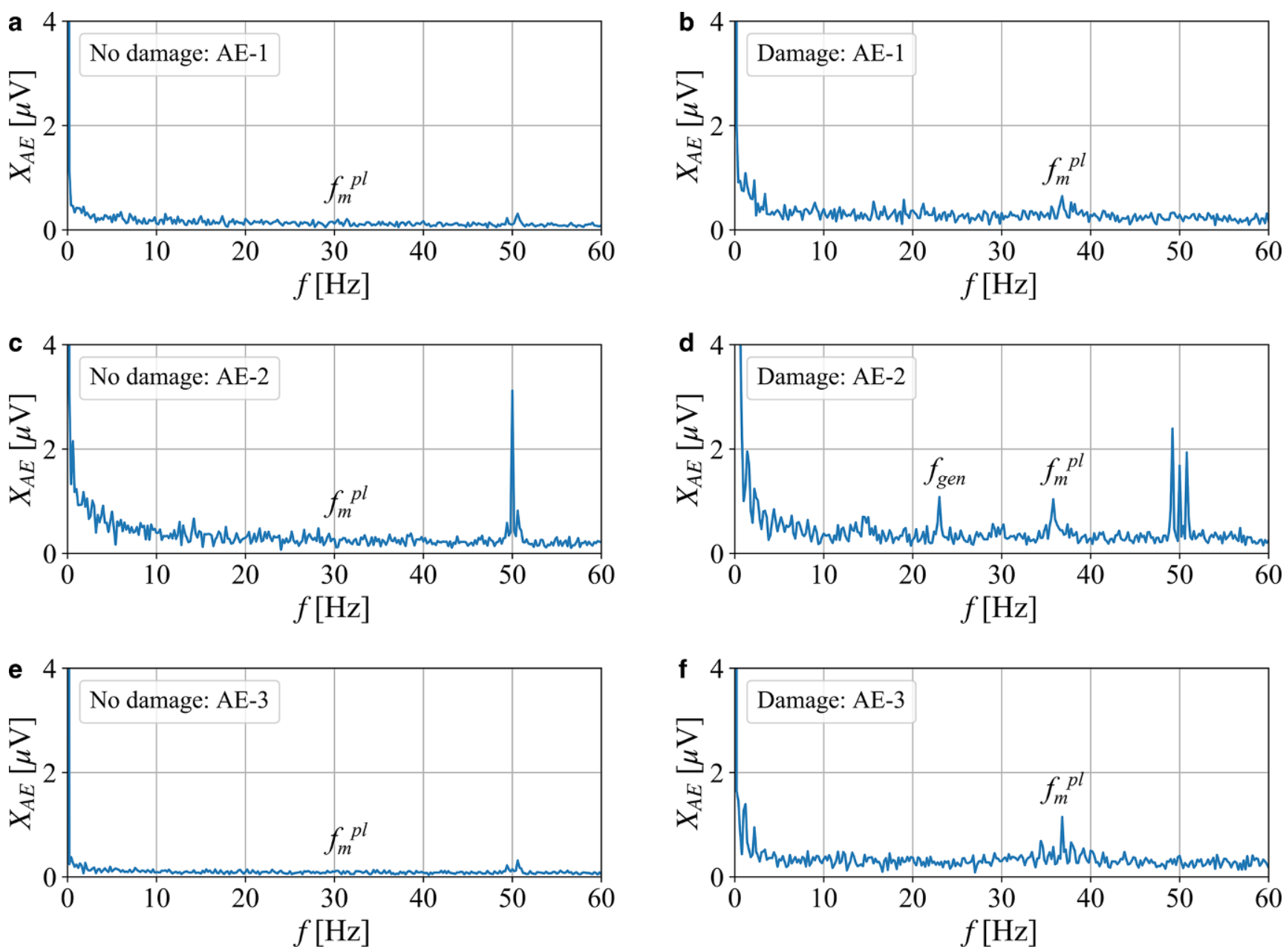

Fig. 8 Envelope spectra of the AE signals for the healthy condition (a, c, e) and for the faulty condition $(\mathbf{b}, \mathbf{d}, \mathbf{f})$

surement position 2 was located on an adjacent bearing. In order to analyze the influence of the sensor-fault distance, we produced an artificial localized fault in the ring gear using a grinding tool as shown in Fig. 2. This fault can be considered as a moderate worn tooth.

We conducted measurements on the test bench considering constant operating conditions. The rotational speed of the high-speed shaft (motor side) was $1300 \mathrm{r} / \mathrm{min}$ and the torque of the low-speed shaft (generator side) was $112 \mathrm{Nm}$. Considering that rotational speed and the geometry of the planetary gearbox, the sun gear rotating frequency was $f_{s}=21.67 \mathrm{~Hz}$, the carrier rotating frequency was $f_{c}=4.33 \mathrm{~Hz}$ and the gear mesh frequency was $f_{m}=312 \mathrm{~Hz}$. Sampling rates of $1 \mathrm{MHz}$ for the $\mathrm{AE}$ signals and $50 \mathrm{kHz}$ for the vibration signals were configured. Besides, a signal acquisition time of $5 \mathrm{~s}$ was set for both. The AE was measured with passive piezoelectric sensors VS375-M which have a main frequency range between 250 and $700 \mathrm{kHz}$. The vibration was measured with piezoelectric accelerometers $603 \mathrm{C} 01$ which have a sensitivity of $100 \mathrm{mV} / \mathrm{g}$ and a main frequency range between 0.5 and $10,000 \mathrm{~Hz}$.

The signal analysis consisted of comparing the Fourier spectra measured at the two measurement points. In order to analyze the magnitude differences from harmonics of operational frequencies in the case of AE signals, the

Table 1 Gear mesh and rotational frequencies for each component

\begin{tabular}{|c|c|c|c|c|c|c|c|}
\hline \multirow[t]{2}{*}{ Case } & \multicolumn{3}{|c|}{ Gear mesh frequency $[\mathrm{Hz}]$} & \multicolumn{4}{|c|}{ Rotational frequency $[\mathrm{Hz}]$} \\
\hline & Planetary $f_{m}^{p l}$ & $1^{\circ}$ parallel $f_{m}^{p a 1}$ & $2^{\circ}$ parallel $f_{m}{ }^{p 2}$ & Rotor $f_{\text {rot }}$ & In. shaft $1 f_{\text {ins } 1}$ & In. shaft $2 f_{\text {ins } 2}$ & Generator $f_{\text {gen }}$ \\
\hline Healthy & 30.61 & 128.97 & 515.87 & 0.31 & 1.77 & 6.14 & 19.1 \\
\hline Faulty & 35.88 & 151.2 & 604.86 & 0.36 & 2.07 & 7.2 & 22.4 \\
\hline
\end{tabular}



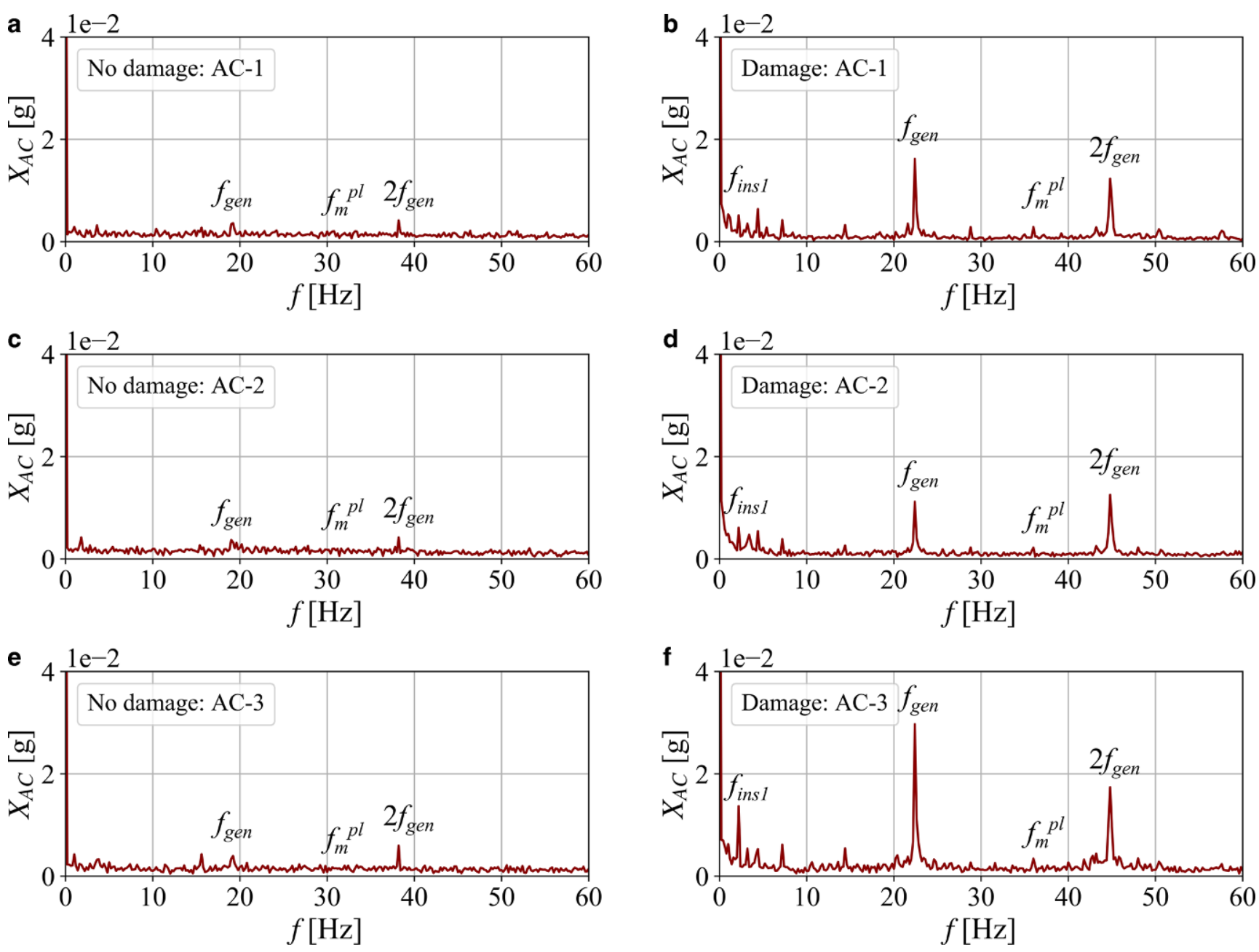

Fig. 9 Spectra of the vibration signals for the healthy condition $(\mathbf{a}, \mathbf{c}, \mathbf{e})$ and for the faulty condition $(\mathbf{b}, \mathbf{d}, \mathbf{f})$

Fourier transformation was applied to the envelope of the AE signals instead of to the signals themselves.

\subsection{Results}

Fig. 3 compares the envelope spectra of the AE signals for the two measurement positions. For the measurement position 1 shown in Fig. 3a the first two harmonics of the gear mesh frequency are clearly visible. These components were expected in account of the AE produced repetitively by the meshing teeth even under healthy conditions. The presence of a fault would increase their magnitudes, although this is not matter of this case study. For this case, the influence of sensor position is investigated. This influence is shown in Fig. 3b, where for the measurement position 2 both harmonics vanished completely.

The same behavior occurs for the spectra of the vibration signals as shown in Fig. 4. For the measurement position 1 shown in Fig. 4a both harmonics are distinguishable in the spectra. However, for the measurement position 2 shown in
Fig. 4b the harmonics are no longer distinguishable comparatively above the background noise.

These obtained results show how effects produced by a fault in the measured signals can be completely missed by an incorrect positioning of the sensors. The results show that the sensors must be located sufficiently near to the fault in order to correctly measured their effects. This behavior occurs not only for the AE signals, but also for the vibration signals. For both techniques a positioning of the sensor direct on the outside of the ring gear should be preferred in order to better measure the effects produced by the meshing teeth and gear faults.

\section{Second case study}

\subsection{Procedure}

For the second case study we analyzed AE and vibration signals measured at three different positions of the plane- 
Fig. 10 Extended spectra of the vibration signals for the faulty condition
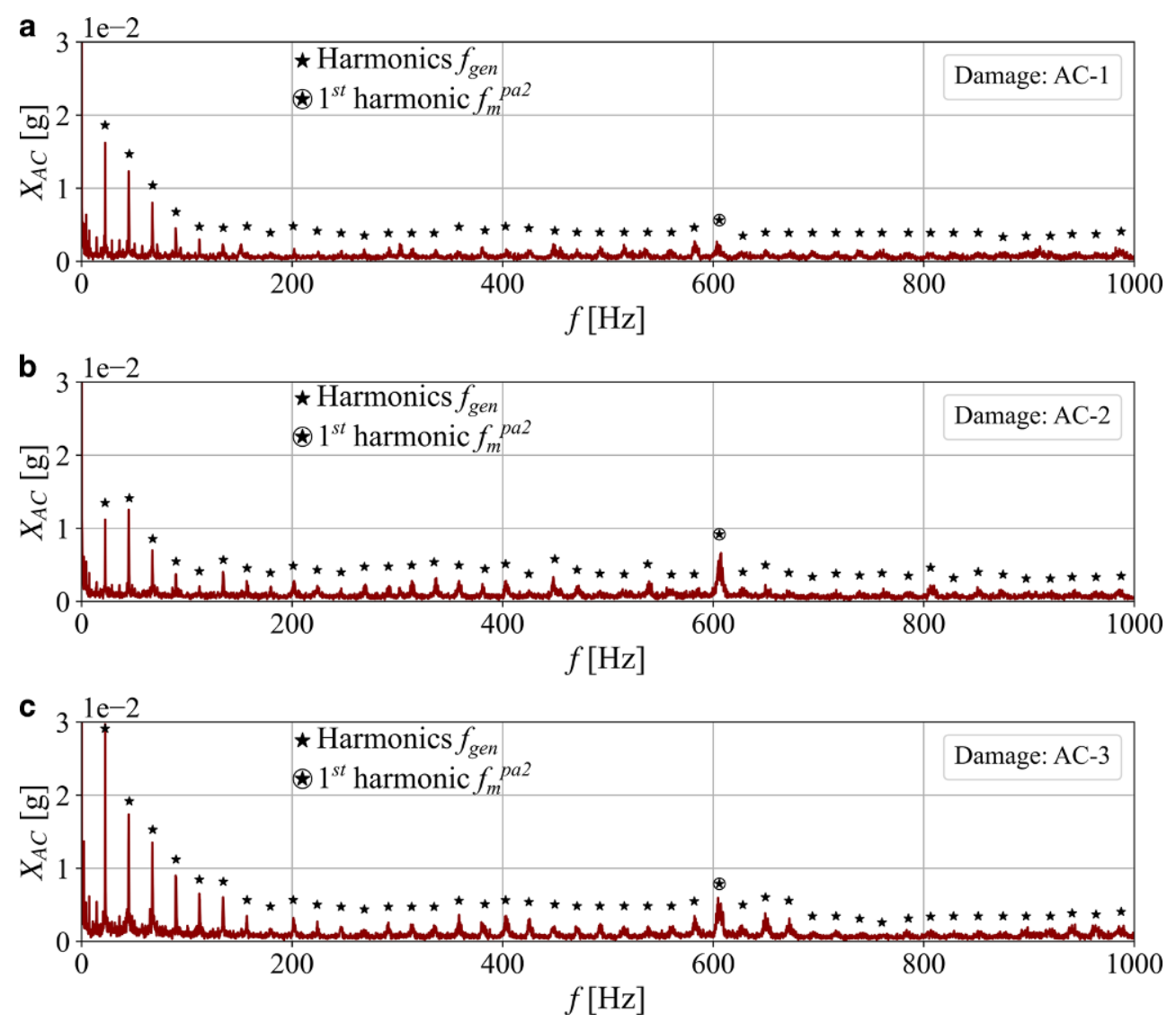

tary stage from a full-size wind turbine gearbox test bench. A schematic view of the gearbox, number of teeth of each gear, location of the fault and measurement positions is shown in Fig. 5. Together with the low-speed planetary stage, the gearbox also had two parallel stages for rotational speed increase. The measurement positions 1, 2 and 3 were circumferential equidistant along the ring gear and were located above the teeth $\mathrm{N}^{\circ} 18, \mathrm{~N}^{\circ} 51$ and $\mathrm{N}^{\circ} 84$, respectively. At each measurement position a pair of one AE sensor and one accelerometer were installed as shown in Fig. 6. The employed sensors corresponded to the same models used for the first case study.

The conducted measurements considered a healthy condition and a faulty condition with damage in one tooth from the the ring gear. The measurements in the healthy condition were conducted considering a rotor rotational speed of $18.6 \mathrm{r} / \mathrm{min}$ and a generator torque of $15 \mathrm{kNm}$. After that, a localized fault was artificially produced in the tooth $\mathrm{N}^{\circ} 1$ of the ring gear from the planetary stage as shown in Fig. 7. This fault can be considered as a small surface defect. Subsequently, the measurements in the faulty conditions were conducted considering a rotor rotational speed of $21.8 \mathrm{r} / \mathrm{min}$ and a generator torque of $30 \mathrm{kNm}$. Due to restrictions of the experimental facilities, it was not possible to carry out the measurements considering the same operating conditions for both cases. Table 1 shows the gear mesh and rotational frequencies for each component of the gearbox considering the operating condition for the healthy and faulty cases.

\subsection{Results}

Fig. 8 shows the envelope spectra of the AE signals for the healthy and faulty conditions for each of the three measurement positions. For the healthy condition (Fig. 8a, c, e) the only visible component in the spectra is a harmonic of $50 \mathrm{~Hz}$, which certainly has its origin on electric noise. For the faulty condition (Fig. 8b, d, f) the first harmonic of the gear mesh frequency of the planetary stage $f_{m}{ }^{p l}=35.8 \mathrm{~Hz}$ is distinguishable for the measurement positions 2 and 3, and also for the measurement position 1 to a lesser extent. This result was expected since the measurement position 1 was the measurement position farthest from the fault. The comparatively magnitude increase of the component at the gear mesh frequency is a symptom that can be related to the induced fault in the ring gear. For the measurement position 2 also a component at $22.4 \mathrm{~Hz}$ is visible. This component corresponds to the rotational frequency of the generator $f_{\text {gen }}$ connected to the output of the 2 nd parallel stage. The appearance of this component can be attributed to the propagation of high-energy AE with an occurrence 
at $f_{g e n}=22.4 \mathrm{~Hz}$ from the $2 \mathrm{nd}$ parallel stage to the planetary stage.

Fig. 9 shows the spectra of the vibration signals for the healthy and faulty conditions for each of the three measurement positions. For the healthy condition (Fig. 9a, c, e), there is only a small component at $38.2 \mathrm{~Hz}$ which corresponds to the 2 nd harmonic of the generator rotational frequency. For the faulty condition (Fig. 9b, d, f), two components at $22.4 \mathrm{~Hz}$ and $44.8 \mathrm{~Hz}$ are clearly distinguishable above the noise level. These frequencies correspond to the first two harmonics of $f_{g e n}$ and have relation with periodic vibrations of the output shaft of the 2nd parallel stage connected to the generator. Therefore, they are not related to the induced damage of the ring gear. The gear mesh component of the planetary stage $f_{m}{ }^{p l}$ at $35.88 \mathrm{~Hz}$ is barely distinguishable above the noise level and its slight magnitude increase can be considered a symptom of the induced damage. Components at the rotational frequency of the 1 st intermediate shaft at $2.07 \mathrm{~Hz}$ are also visible, which also do not have relation with the induced fault.

In order to further analyze the magnitude increases of the first two harmonics $f_{g e n}$ for the vibration signals, in Fig. 10 the extended spectra for the faulty condition are shown. It is noticed that several harmonics of the rotational frequency of the generator $f_{\text {gen }}$ connected to the output shaft of the 2 nd parallel stage are excited. The component at the gear mesh frequency of the second parallel stage $f_{m}{ }^{p 2}$ is also visible, but it has low amplitude in comparison with the other components. These observations in the vibration spectra are typical symptoms of a mechanical looseness or misalignment between output of the 2nd parallel stage and generator. This could have been caused by changes in the mounting conditions for the second set of measurements (faulty condition).

These obtained results showed that the ring gear fault in the planetary stage can be detected with higher certainty if an $\mathrm{AE}$ analysis of the envelope spectra is conducted together with the traditional spectral analysis of vibrations. The fault produced a magnitude increase of the component at the gear mesh frequency of the $\mathrm{AE}$ signal envelope spectra. However, the spectral analysis of vibration signals showed only slight differences between the healthy and faulty cases that could be attributed to the fault in the ring gear. Some other magnitude increases were attributed rather to changes in the mounting conditions in account of their frequencies.

\section{Discussion}

This research presented two case studies comparing the analysis of AE signals and vibrations for gear fault diagnosis in planetary gearboxes. As it has been established by several investigations in the research field, the spectral anal- ysis is a powerful tool that allows to evaluate the magnitudes of mechanical oscillations at different frequencies. By evaluating the magnitudes of operational frequencies, possible damage in different components from a machine can be detected. Since the AE signals have frequencies much higher than regular operational frequencies, its spectral analysis must be conducted on the envelope of the signal rather than on the signal itself.

In the first case study, the results indicated that symptoms of a fault in the $\mathrm{AE}$ signals and also in the vibration signals can vanish almost completely if the sensor is not near enough to the fault. In the conducted experiments, the signals measured by the AE sensor and accelerometer located on a nearby bearing did not show clear symptoms to detect the fault, which was not the case for the sensors installed direct on the planetary gearbox. One important factor to consider is the flexible coupling located between gearbox and bearing. On one hand, the coupling adds many interfaces that decrease the transmission of the AE signals since many reflections take place. On the other hand, the coupling modifies greatly the transfer function for the vibration signals since the stiffness, damping and mass of the system change. This result leads to a valuable recommendation for the selection of sensor positions in planetary gearboxes.

In the second case study, the detection of a ring gear fault from a low-speed planetary stage of a wind turbine gearbox was investigated. The conducted analysis indicated that the fault could be detected clearer in the AE signals than in the vibration signals. Since the fault corresponded to a mild surface defect in one tooth, the hypothesis to explain these results is that the fault did not produced noticeable changes neither in the stiffness nor the profile of the tooth that affect the vibratory response. However, at a microscopical level the fault increased the friction between teeth which contributed to generate a higher level of AE produced by the meshing process even for low speed conditions.

\section{Conclusions}

The present research compared the detection of ring gear faults in planetary gearboxes using AE and vibrations. From the two investigated cases studies we can conclude that:

- The sensors should be located as near as possible to the component of the gearbox to be monitored. The installation of sensors outside the ring gear is an appropriate option, while the installation of sensors on bearings leaving a coupling between sensor and gearbox should be avoided.

- The detection of small surface defects in the low-speed planetary stage from wind turbine gearboxes may not be 
successful if only the measurement of vibrations is considered. Due to the nature of vibrations and the low rotational speeds in the planetary stage, the effects of such fault will only be noticeable when the fault is big enough to considerably modify the stiffness or profile of the defected tooth.

- Such defects can be better detected by the measurement of AE. Due to the nature of the AE generation, any condition that increases the friction between teeth could be detected by the AE analysis.

- Such small surface defects can afterwards lead to an important fault such as cracks, pitting of fracture. Therefore, the measurement of $\mathrm{AE}$ is an important complementary tool to increase the diagnostic capability of condition monitoring systems based on vibration analysis.

Acknowledgements The authors would like to acknowledge the contributions from Mr. Steffen Hinderer and Mr. Brian Rieckhoff to this publication.

Funding Open Access funding enabled and organized by Projekt DEAL.

Open Access This article is licensed under a Creative Commons Attribution 4.0 International License, which permits use, sharing, adaptation, distribution and reproduction in any medium or format, as long as you give appropriate credit to the original author(s) and the source, provide a link to the Creative Commons licence, and indicate if changes were made. The images or other third party material in this article are included in the article's Creative Commons licence, unless indicated otherwise in a credit line to the material. If material is not included in the article's Creative Commons licence and your intended use is not permitted by statutory regulation or exceeds the permitted use, you will need to obtain permission directly from the copyright holder. To view a copy of this licence, visit http://creativecommons.org/licenses/by/4. $0 /$.

\section{References}

1. Lacal-Arantegui R (2019) Globalization in the wind energy industry: contribution and economic impact of European companies. Renew Energy 144:109270

2. Scheu M, Tremps L, Smolka U (2019) A systematic failure mode effects and criticality analysis for offshore wind turbine systems towards integrated condition based maintenance strategies. Ocean Eng 176:118-133

3. Tchakoua P, Wamkeue R, Ouhrouche $M$ et al (2014) Wind turbine condition monitoring: state-of-the-art review, new trends, and future challenges. Energies 7(4):2595-2630

4. Wang T, Han Q, Chu F et al (2019) Vibration based condition monitoring and fault diagnosis of wind turbine planetary gearbox: a review. Mech Syst Signal Process 126:663-685

5. Garg N, Sharma O, Kumar A et al (2012) A novel approach for realization of primary vibration calibration standard by homodyne laser interferometer in frequency range of $0.1 \mathrm{~Hz}$ to $20 \mathrm{kHz}$. Measurement 45(8):1941-1950

6. Meng Z, Shi G, Wang F (2020) Vibration response and fault characteristics analysis of gear based on time-varying mesh stiffness. Mech Mach Theory 148:103786
7. Lu B, Li Y, Wu X et al (2009) A review of recent advances in wind turbine condition monitoring and fault diagnosis. In: IEEE power electronics and machines in wind applications. IEEE, Lincoln

8. Salameh J, Cauet S, Etien E et al (2018) Gearbox condition monitoring in wind turbines: a review. Mech Syst Signal Process 111:251-264

9. Kim Y, Tan A, Kosse V (2008) Condition monitoring of low-speed bearings - a review. Aust J Mech Eng 6(1):61-68

10. Hellier C (2003) Handbook of nondestructive evaluation. McGrawHill, New York

11. Coronado D, Fischer K (2015) Condition monitoring of wind turbines: State of the art, user experience and recommendations. Project report. Fraunhofer Institute for Wind Energy and Energy System Technology, Bremerhaven

12. Tan C (2005) Identification of the acoustic emission source during a comparative study on diagnosis of a spur gearbox. Tribol Int 38(5):469-480

13. Novoa AB, Vicuña CM (2016) New aspects concerning the generation of acoustic emissions in spur gears, the influence of operating conditions and gear defects in planetary gearboxes. Insight 58(1):18-27

14. Tan C, Mba D (2005) Correlation between acoustic emission activity and asperity contact during meshing of spur gears under partial elastohydrodynamic lubrication. Tribol Lett 20(1):63-67

15. Ferrando Chacon J, Artigao Andicoberry E, Kappatos V et al (2016) An experimental study on the applicability of acoustic emission for wind turbine gearbox health diagnosis. J Low Freq Noise Vib Active Control 35(1):64-76

16. Leaman F (2020) Contributions to the diagnosis and prognosis of ring gear faults of planetary gearboxes using acoustic emissions. Doctoral thesis, RWTH Aachen University, Germany

17. Loutas T, Sotiriades G, Kalaitzoglou I et al (2009) Condition monitoring of a single-stage gearbox with artificially induced gear cracks utilizing on-line vibration and acoustic emission measurements. Appl Acoust 70(9):1148-1159

18. Tan C, Irving P, Mba D (2007) A comparative experimental study on the diagnostic and prognostic capabilities of acoustic emission, vibration and spectrometric oil analysis for spur gears. Mech Syst Signal Process 21(1):208-233

19. Eftekharnejad B, Mba D (2009) Seeded fault detection on helical gears with acoustic emission. Appl Acoust 70(4):547-555

20. Mishra C, Samantaray A, Chakraborty G (2017) Rolling element bearing fault diagnosis under slow speed operation using wavelet de-noising. Measurement 103:77-86

21. Song L, Wang H, Chen P (2018) Vibration-based intelligent fault diagnosis for roller bearings in low-speed rotating machinery. IEEE Trans Instrum Meas 67(8):1887-1899

22. Jin C (2018) Experimental study of low-speed gearbox faults using vibration and acoustic emission signals. Master thesis, Queen's University, Canada

23. Kim E, Tan A, Mathew J et al (2008) Condition monitoring of low speed bearings: a comparative study of the ultrasound technique versus vibration measurements. Aust J Mech Eng 5(2):177-189

24. Gao L, Zai F, Su S et al (2011) Study and application of acoustic emission testing in fault diagnosis of low-speed heavy-duty gears. Sensors 11(1):599-311

25. Molina Vicuña C (2009) Contributions of the analysis of vibrations and acoustic emissions for the condition monitoring of epicyclic gearboxes. Doctoral thesis, RWTH Aachen University, Germany 